'Programa de Especialización en Medicina Interna, Escuela de Graduados, Facultad de Medicina, Universidad Austral de Chile. Valdivia, Chile. ${ }^{2}$ Subdepartamento de Medicina, Hospital Base de Valdivia. Valdivia, Chile. IInstituto de Medicina, Facultad de Medicina, Campus Isla Teja, Universidad Austral de Chile. Valdivia, Chile. ${ }^{4}$ Laboratorio de Biología Molecular. Hospital Base de Valdivia. Valdivia, Chile.

Trabajo no recibió financiamiento. Los autores declaran no tener conflictos de interés.

Recibido el 23 de marzo de 2020, aceptado el 18 de mayo de 2020 .

Correspondencia a: Dr. Alberto Fica Subdepartamento de Medicina, Hospital Base de Valdivia. Bueras 1003, Valdivia, Región de Los Ríos, Chile. albertoficacubillos@gmail.com

\section{Cytomegalovirus infection in AIDS patients. An illustrative case series}

\author{
ROBERTO MONDACA ${ }^{1}$, ALBERTO FICA ${ }^{2,3}$, IGNACIO DELAMA ${ }^{2,3}$, \\ FELIPE OLIVARES ${ }^{2}$, MARITZA NAVARRETE ${ }^{4}$
}

\begin{abstract}
Background: Cytomegalovirus (CMV) is an opportunistic infection (OI) in immunosuppressed patients. However, there are no clear cut-off values available for quantitative plasmatic CMV measures (viral load [VL]) to discriminate those with CMV illness from those infected suffering a transient viral reactivation. Aim: To estimate a CMV VL cut-off point that discriminates infected patients and those with CMV related diseases, and to clinically characterize AIDS patients with this OI. Patients and Methods: Retrospective analysis of AIDS patients admitted by any reason between years 2017 and 2019 and who had a positive plasma CMV VL at any titer. Cases were categorized with illness or infected using accepted criteria and the cut-off value was obtained by receiver operating characteristic curve (ROC) analysis. Results: Twelve patients were identified as having a $C M V$-associated illness and seven with CMV infection. A CMV VL of 3,800 copies $/ \mathrm{mL}$ had a sensitivity of $91.6 \%$ and $100 \%$ specificity to discriminate both states. Of the 12 patients with CMV illness, all were in AIDS stage and only five were receiving HIV therapy. Predominant clinical presentations were gastrointestinal (50\%), followed by liver involvement (25\%) and CMV disease (25\%). All patients were treated with ganciclovir or valganciclovir. Ten patients had a favorable response (83.3\%), one patient only had a laboratory improvement (8.3\%) and one died during treatment (8.3\%). Drug toxicity was recorded in nine patients but in only three cases, a dose adjustment was necessary. Conclusions: The predominant clinical manifestation in our series was gastrointestinal. A CMV VL cutoff level of CMV VL of 3,800 copies / $\mathrm{mL}$ is useful to discriminate infected patients from those with CMV related disease.

(Rev Med Chile 2020; 148: 778-786)
\end{abstract}

Key words: Acquired Immunodeficiency Syndrome; Cytomegalovirus; $\mathrm{Pa}-$ tient Outcome Assessment; ROC Curve; Drug-Related Side Effects and Adverse Reactions.

\section{Infección por citomegalovirus en pacientes con SIDA. Una serie ilustrativa}

Antecedentes: Citomegalovirus (CMV) es una infección oportunista (IO) en pacientes inmunosuprimidos. Sin embargo, se requieren puntos de corte de carga viral (CV) para discriminar a aquellos con enfermedad por $C M V$ de aquellos infectados que sufren una reactivación viral transitoria. Objetivos: Estimar un punto de corte de la CV de CMV que discrimine a los enfermos de los infectados $y$, además, caracterizar clínicamente a los pacientes con sida que 
presentan esta IO. Pacientes y Métodos: Análisis retrospectivo de pacientes con sida hospitalizados por cualquier motivo entre los años 2017 y 2019, y que presentaron un CV de CMV plasmática positiva a cualquier título. Los casos se clasificaron como enfermos utilizando criterios aceptados y el valor de corte se obtuvo mediante análisis de una curva ROC. Resultados: Durante el periodo de estudio, 12 pacientes fueron identificados con enfermedad asociada al CMVy siete con infección. Una CV de 3.800 copias/ml logró una sensibilidad de 91,6\% y una especificidad de 100\% para discriminar ambos estados. De los 12 pacientes enfermos, todos estaban en etapa de sida y solo 5 recibían terapia contra el VIH. La presentación clínica predominante fue gastrointestinal (50\%) seguida del compromiso hepático (25\%) y de la enfermedad por CMV (25\%). Todos los pacientes fueron tratados con ganciclovir o valganciclovir. Diez pacientes tuvieron una respuesta favorable (83,3\%), uno solo tuvo mejoría de laboratorio $(8,3 \%)$ y otro paciente falleció durante el tratamiento (8,3\%). Nueve pacientes evolucionaron con toxicidad farmacológica, pero en solo 3 casos fue necesario ajustar las dosis. Conclusiones: La forma predominante de presentación de la enfermedad fue gastrointestinal. Un punto de corte de 3.800 copias/ml discrimina pacientes infectados de aquellos con la enfermedad.

Palabras clave: Citomegalovirus; Sindrome Inmunodeficiencia Adquirida; Curva ROC; Efectos adversos asociados a drogas y reacciones adversas, evaluación desenlace.

T The epidemiological expansion of HIV/AIDS in Chile with patients debuting in advanced stages of the disease maintains the clinical relevance and burden of opportunistic infections (OI). This phenomenon occurs in clear contrast with their marked decrease in countries that have achieved a successful introduction of combined antiretroviral therapy programs ${ }^{1-3}$.

Cytomegalovirus (CMV) is an AIDS-defining illness affecting different organs (for example retinitis or colitis) or by a febrile disease associated with hematological alterations with or without increased serum transaminases denominated CMV disease. These complications arise by viral reactivation secondary to advanced immunosuppression, however, asymptomatic transient reactivation events also can occur, which turned to be evident when quantitative techniques in blood or plasma samples are incorporated ${ }^{4-6}$. Distinction between disease and reactivation is necessary in every suspicious case to avoid overtreatment for CMV in a patient who has another cause for the symptoms. In this way, using appropriate criteria and local validations, the quantitative techniques for CMV allow to discriminate between infection and illness and also to evaluate the response to a specific treatment.
Some publications on immunosuppressed patients affected by CMV in Chile have evaluated viral loads in a quantitative manner to identify patients with CMV illness ${ }^{7,8}$. Although a comparison between CMV diseased versus asymptomatic patients $^{6}$, no clear cut-off points to distinguish infection from disease in routine clinical settings are available for AIDS patients in our country. Besides, a more detailed clinical information on the symptoms associated with CMV in AIDS patients, their response to therapy, viral clearance and outcome is desirable. In addition, it is not known if patients with this OI belong to newly-diagnosed AIDS patients or whether they are part of those who discontinued their HIV treatment, and are somehow preventable cases.

\section{Patients and Methods}

\section{Study design}

Retrospective-descriptive design. Cases were detected among those HIV/AIDS patients admitted by any reason at the Hospital Base de Valdivia between 2017 and 2019 and who presented a positive CMV viral load (VL) in plasma at any titer. A quantitative CMV analysis was not available before year 2017 . 


\section{Discrimination between diseased and infected patients and cut-off point calculation}

Cases were classified with illness using as a reference criteria available for patients with solid organ transplants or hematopoietic precursors ${ }^{9}$. The following categories were defined a priori: CMV disease (fever with leukopenia or thrombocytopenia and a positive test for CMV after ruling out other etiologies); gastrointestinal disease (gastrointestinal symptoms, associated with mucosal lesions and demonstration of virus infection in an endoscopic or surgical biopsy; the case was classified as probable in case of a favorable response to treatment if biopsy was not available); hepatitis (bilirubin and liver serum transaminases increase); probable pneumonia (positive test for CMV and signs and symptoms of lung disease, in the absence of other etiologies, and/or bronchoalveolar lavage with positive test); and retinitis (characteristic injury confirmed by an ophthalmologist).

Determination of the cut-off point to discriminate infected from diseased patients was made by constructing a ROC curve. Comparisons of some variables between diseased and infected patients were performed using nonparametric tests for independent groups (Mann-Whitney test).

\section{VL measurement}

CMV VL was performed through quantitative real-time polymerase chain reaction (RT-PCR) from plasma samples performed at the Laboratorio de Biología Molecular from Hospital Base de Valdivia. Total nucleic acids were extracted using a MagNA Pure Compact Nucleic Acid Isolation Kit I on the MagNA Pure Compact Instrument (Roche Diagnostics GmbH, Germany), following manufacturer's instructions. Amplification was done in real time with primers and probes included in the SACACE Quantitative CMV Kit (Sacace Biotechnologies, Como, Italy) and the amplification reaction was performed in CFX 96 Touch $^{\mathrm{TM}}$ Real-Time PCR Detection System (BIO-RAD, California, USA) according to the manufacturer's instructions. CMV detection threshold was 400 copies/mL (2.6 log copies/ $\mathrm{mL})$. The linear detection range was from 500 to $10,000,000$ copies/mL (2.7 log-7 log copies/ $\mathrm{mL})$. Positive values but $<500$ copies/mL were interpolated to an intermediate value to facilitate quantitative analysis.

\section{Characterization of cases assigned as diseased}

A descriptive analysis of clinical, laboratory, treatment and hospital mortality related variables was performed in the group with end-organ compromise or CMV disease. Data are presented as a percentage in the case of categorical variables and as a median and interquartile range (25-75\%) for continuous variables. Response to CMV therapy was categorized as favorable if associated with clinical improvement and a decline in CMV VL, laboratory response (only CMV VL decrease) or as failure in the event of persistent clinical manifestations or death.

\section{Bone marrow and renal toxicity associated to CMV therapy}

Ganciclovir (GCV)/valganciclovir (valGCV) related toxicity was measured on neutrophil and platelet counts. Neutrophil toxicity was defined as a decline of $\geq 50 \%$ of the baseline value or a decrease to $<1,000$ neutrophils $/ \mu \mathrm{L}^{10}$. Platelet toxicity was defined by a decrease below the lower normal value $(150,000 / \mu \mathrm{L})$ or a drop $>25 \%$ if the baseline was already decreased. To identify treatment associated nephrotoxicity we used the KDIGO (Kidney Disease Improving Global Outcomes) criteria ${ }^{11}$.

\section{Ethical issues}

This work was approved by the Comite de Ética Científica, Servicio de Salud de Valdivia.

\section{Results}

Cases, comparison between infected and diseased patients and cut-off value to discriminate between CMV infection or illness

Between 2017 and 2019, 21 admitted patients were studied for CMV with a positive plasmatic VL result in the period ( 16 men, 5 women; middle age 37 years). After a careful clinical analysis, 12 patients were cataloged with disease $(57.1 \%)$ and the rest with infection only (42.9\%). Patients with infection in whom CMV illness was discarded included one each of the following clinical conditions: fever in a patient with progressive multifocal leukoencephalopaty, jaundice secondary to acute hepatitis B infection, fever and diarrhoea, community acquired pneumonia with diarrhoea, colonic intestinal perforation (CMV biopsy negative), pancytopenia by disseminated atypical mycobacteriosis, community acquired pneumonia, 
cryptococcal meningitis, and haemophagocytic syndrome associated to lymphoma. In all of them low copy numbers were obtained.

The cut-off point by ROC curve to discriminate both states was 3,800 copies $/ \mathrm{mL}$ in plasma (log 3.58, Area Under the Curve [AUC] 0.96; $\mathrm{p}<0.001$, Figure 1). CMV VL in diseased patients had a median of 112,133 copies/mL (log 5.05) versus 249 in those only infected $(\log 2.40)(\mathrm{p}<0.001$ Mann Whitney test). Sensitivity of a CMV VL $>3,800$ copies/mL to detect CMV patients with illness was $91.6 \%$ and its specificity was $100 \%$.
A trend towards a higher HIV viral load was observed among patients with CMV illness versus those only infected with median values of $774,500(\log 5.89)$ vs 350,334 (log 5.54) copies/ $\mathrm{mL}$ but these differences were not significant (Table 1). Likewise, no significant differences were detected both in total lymphocyte count or in CD4 lymphocyte count between CMV diseased patients and those only infected (median 28.5 vs $32.5 / \mu \mathrm{L}$, respectively, Table 1 ). Furthermore, no differences were detected in lactic dehydrogenase, bilirubin, serum transaminases or plasmatic

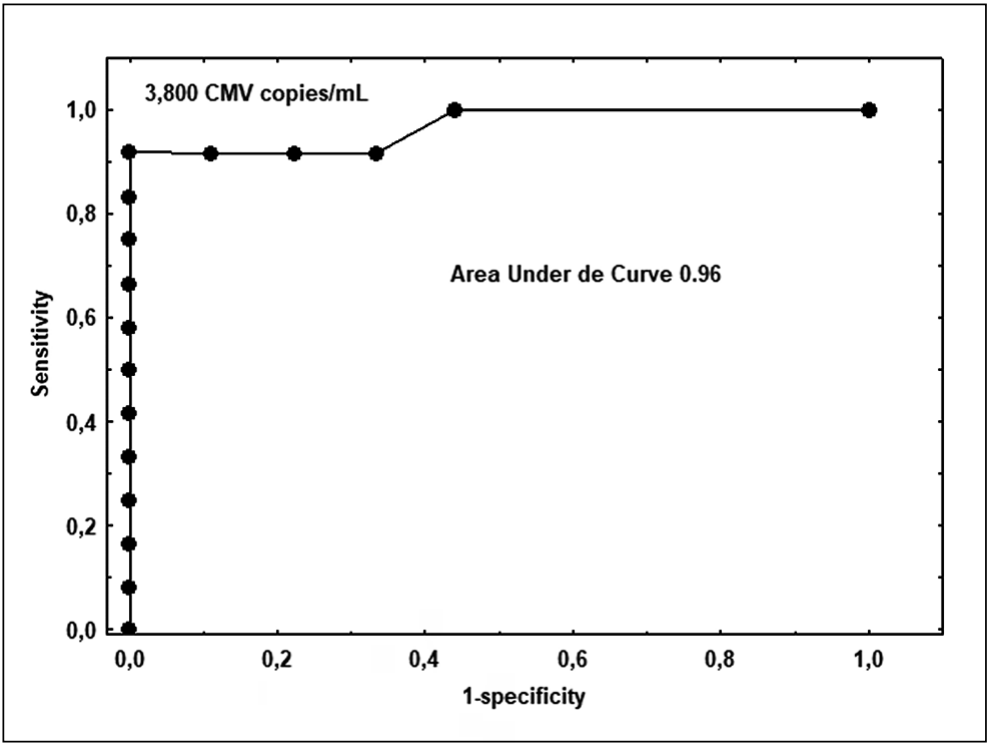

Figure 1. ROC analysis of CMV viral loads to discriminate patients with end-organ compromise or CMV disease versus only-infected patients.

Table 1. Comparison of selected clinical and laboratory parameters between CMV diseased and infected patients. Hospital Base de Valdivia, 2017-2019

\begin{tabular}{|c|c|c|c|}
\hline Parameter & $\begin{array}{l}\text { CMV illness (end-organ or } \\
\text { CMV disease) } n=12^{*}\end{array}$ & $\begin{array}{l}\text { CMV infection } \\
n=9 *\end{array}$ & $\mathbf{p}^{* *}$ \\
\hline Age in years $(p 25-75)$ & $45(38.5-57)$ & $31(30-35)$ & 0,02 \\
\hline AIDS stage $n / N$ & $12 / 12$ & $8 / 9$ & ns \\
\hline Receiving ART n/N & $5 / 12$ & $3 / 9$ & ns \\
\hline$C D 4 / \mu \mathrm{L} \quad(p 25-75)$ & $28.5(12-54)$ & $32.5(30-74)$ & ns \\
\hline HIV viral load (p25-75) & $\log 5,89 \quad(5.33-6.42)$ & $\log 5.54 \quad(5.11-5.97)$ & ns \\
\hline 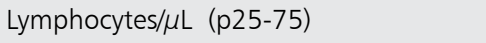 & $800 \quad(350-1,000)$ & $800 \quad(700-1,000)$ & ns \\
\hline Platelets/ $\mu \mathrm{L}$ (p25-75) & $161,000 \quad(99,999-232,000)$ & $332,000 \quad(247,000-496,000)$ & $<0.001$ \\
\hline CMV viral load copies/mL (log and IQR) & $112,133(\log 5.05 ; 4.49-5.62)$ & $249(\log 2.40 ; 240-275)$ & $<0.001$ \\
\hline
\end{tabular}

*For quantitative variables, results are expressed as medians and interquartil range $25-75 \%$ (IQR). **Fisher test for categorical variables and Mann-Whitney test for continuous variables; ns: not significant. 
creatinine values between both groups (data not shown). In contrast, the non-parametric Mann Whitney test indicated an older age in patients with CMV illness (median 45 vs 31 years in those infected, $\mathrm{p}=0.02$ ) and a lower platelet count in CMV diseased patients (median 161,000 vs 332,000 in diseased versus infected, respectively, $\mathrm{p}=0.01$, Table 1 ). The discrimination capacity of this difference was more limited than CMV VL. ROC analysis indicated an AUC of 0.82 for a cut-off value $<230,000$ platelets/ $\mu \mathrm{L}$. Applying this breakpoint, the sensitivity was $75 \%$ and its specificity was $88.9 \%$ to recognize CMV illness.

\section{Time trend for CMV patients}

The number of cases increased progressively between 2017 and 2019, with 3, 4 and 5 cases respectively, but this trend did not reach statistical significance (Spearman correlation analysis).

\section{Characterization of diseased patients}

For the group of 12 patients with CMV illness, their average age was 47.5 years, with 10 male patients (83.3\%), all in AIDS stage (Table 2). Only 5 patients were on antiretroviral therapy (ART, $41.7 \%)$, one had abandoned it $(8.3 \%)$ and $6(50 \%)$ had never received it. In the group without ART, 3 patients knew the diagnosis but were not in control and the other 3 were admitted by an AIDS-associated condition $(25 \%)$. In 8 cases CMV caused hospitalization (75\%) and in the rest the disease appeared after admission. In turn, in half of the CMV cases, it was associated with another OI. The most relevant clinical manifestations were fever (83.3\%), diarrhea (58.3\%), and abdominal pain (54.5\%). In addition, 2 presented hematochezia and 2 jaundice (16.7\% each). Laboratory tests revealed leukopenia $(50 \%)$, low platelet count (33.3\%) and hypoalbuminemia (75\%). Some patients presented increases in serum transaminase values $(41.7 \%$ for SGOT, maximum value 114 IU/L) and alkaline phosphatases (50\%, maximum value $444 \mathrm{IU} / \mathrm{L})$ (Table 2).

\section{Clinical presentation and management}

The predominant presentation in this series was gastrointestinal (50\%; 5 probable cases, one confirmed by biopsy) followed by cholestatic liver involvement $(25 \%)$ and CMV disease without organic involvement $(25 \%$, Table 3$)$. Five patients required Critical Care Unit management (41.7\%),
Table 2. General features and clinical manifestations among 12 patients with AIDS and CMV end-organ compromise or CMV disease. Hospital Base de Valdivia 2017-2019

\begin{tabular}{|c|c|}
\hline Parameter & Results \\
\hline Age, median value & 45 years \\
\hline Male sex & $10(83.3 \%)$ \\
\hline \multicolumn{2}{|l|}{ CDC Stage } \\
\hline B3 & $1 \quad(8.3 \%)$ \\
\hline $\mathrm{C3}$ & $11(91.7 \%)$ \\
\hline \multicolumn{2}{|l|}{ ART } \\
\hline Receiving ART & $5(41.7 \%)$ \\
\hline Abandoned ART & $1(8.3 \%)$ \\
\hline Without ART & $6(50 \%)$ \\
\hline \multicolumn{2}{|l|}{$\begin{array}{l}\text { Cause of admission and association } \\
\text { with other OI }\end{array}$} \\
\hline CMV caused admission & $8(75 \%)$ \\
\hline CMV appeared after admission & $4(25 \%)$ \\
\hline Association with other $\mathrm{Ol}$ & $6(50 \%)$ \\
\hline \multicolumn{2}{|l|}{ Symptoms } \\
\hline Fever & $10(83.3 \%)$ \\
\hline Diarrhoea & $7(58.3 \%)$ \\
\hline Abdominal pain & $6(54.5 \%)$ \\
\hline Hematochezia & $2(16.7 \%)$ \\
\hline Jaundice & $2(16.7 \%)$ \\
\hline \multicolumn{2}{|l|}{ Laboratory } \\
\hline Leukopenia $<4,500 / \mu \mathrm{L}$ & $6(50 \%)$ \\
\hline Thrombocytopenia $<150,000 / \mu \mathrm{L}$ & $4(33.3 \%)$ \\
\hline Hypoalbuminemia < 3.5 g/dL & $9(75 \%)$ \\
\hline Increased SGOT > $40 \mathrm{UI} / \mathrm{L}^{*}$ & $5(41.7 \%)$ \\
\hline Increased SGPT > $41 \mathrm{UI} / \mathrm{L}^{*}$ & $4(33.3 \%)$ \\
\hline Increased alkaline phosphatases > $129 \mathrm{UI} / \mathrm{L}$ & $6(50 \%)$ \\
\hline Hyperbilirrubinemia $>1 \mathrm{mg} / \mathrm{dL}$ & $3(25 \%)$ \\
\hline Increased blood urea nitrogen $>20 \mathrm{mg} / \mathrm{dL}$ & $3(25 \%)$ \\
\hline Elevated plasmatic creatinine $>1 \mathrm{mg} / \mathrm{dL}$ & $3(25 \%)$ \\
\hline
\end{tabular}

*SGOT: serum glutamate oxaloacetate transaminase; SGPT: serum glutamate pyruvate transaminase. ART: antiretroviral therapy.

two underwent surgery $(16.7 \%)$ and 50\% required transfusions. No one reported visual symptoms to suspect retinitis. The 12 identified patients were treated with GCV or valGCV (average duration of therapy 22 days, range 3-43 days) with diffe- 
Table 3. Clinical syndrome, management, drug toxicity and outcomes associated to CMV illness among 12 patients at the Hospital Base de Valdivia, 2017-2019

\begin{tabular}{|c|c|}
\hline Parameter & Results \\
\hline \multicolumn{2}{|l|}{ Clinical syndrome } \\
\hline Gastrointestinal & $6(50 \%)$ \\
\hline Hepatic & $3(25 \%)$ \\
\hline CMV disease* & $3(25 \%)$ \\
\hline \multicolumn{2}{|l|}{ Hospitalization unit } \\
\hline Critical Care (ICU or Intermediate Care Unit) & $5(41.7 \%)$ \\
\hline General ward & $7(58.3 \%)$ \\
\hline \multicolumn{2}{|l|}{ CMV antiviral therapy } \\
\hline GCV only (intravenous) & $4(33.3 \%)$ \\
\hline Sequential GCV-ValGCV therapy & $6(50 \%)$ \\
\hline ValGCV only & $2(16.7 \%)$ \\
\hline $\begin{array}{l}\text { Median induction therapy length in days } \\
\text { (range) }\end{array}$ & $20(3-43)$ \\
\hline Switch to maintenance therapy & $9(75 \%)$ \\
\hline \multicolumn{2}{|l|}{ Other therapies } \\
\hline Ventilatory support & $2(16.7 \%)$ \\
\hline Surgical procedures & $2(16.7 \%)$ \\
\hline Transfusions & $6(50 \%)$ \\
\hline \multicolumn{2}{|l|}{ Response to CMV therapy } \\
\hline Favorable & $10(83.3 \%)$ \\
\hline Laboratory only & $1(8.3 \%)$ \\
\hline Non response/deceased & $1(8.3 \%)$ \\
\hline \multicolumn{2}{|l|}{ Drug related toxicity } \\
\hline Neutropenia & $8(66.7 \%)$ \\
\hline Thrombocytopenia & $3(25 \%)$ \\
\hline Acute renal injury & $2(16.7 \%)$ \\
\hline \multicolumn{2}{|l|}{ Outcome } \\
\hline Discharged alive & $11(91.6 \%)$ \\
\hline Deceased & $1(8.3 \%)$ \\
\hline CMV recurrence & $2(16.7 \%)$ \\
\hline
\end{tabular}

*fever + leukopenia/thrombocytopenia. rent parenteral-oral schedules in the induction phase and $75 \%$ switched to maintenance therapy (Table 3).

\section{Response to treatment and evolution}

Ten patients had a favorable response to treatment $(83.3 \%)$, one had only laboratory improvement and another died during treatment $(8.3 \%$, Table 3$)$. The remaining 11 patients were discharged alive $(91.6 \%)$. The cause of death in the deceased patient was multifactorial with CMV, cryptococcosis, and nosocomial candidemia. The patient was admitted to ICU and connected to mechanical ventilation. Two patients presented recurrence of the disease $(16.7 \%)$, both without switching to maintenance therapy. Viral clearance was observed in 10 of the 11 patients with at least one follow-up sample (Figure 2). In one case, an initially low CMV value $(<900$ copies $/ \mathrm{mL})$ increased in the second control, which motivated the start of treatment for CMV. The first CMV control was performed at a median of 11 days (range 6-22 days). The patient who died presented an extreme high initial CMV value but died 3 days later without follow-up.

\section{Hematological and renal toxicity}

A decrease in the neutrophil count was detected in 8 of 12 patients (75\%) during follow-up (Figure 3 ) and in $3(25 \%)$ a drop on the platelet count. Only in 2 patients an increase in plasma creatinine $>0.3 \mathrm{mg} / \mathrm{dL}$ above baseline values $(16.7 \%)$ was detected (Table 3$)$. The decrease in the neutrophil count was progressive over time (Figure 2). Only in 3 of the total of 9 patients with bone marrow or renal toxicity, the doses of GCV or valGCV were diminished.

\section{Discussion}

In this work, a comparison between CMV diseased patients and those only infected was carried out including patients admitted with symptoms and/or laboratory abnormalities suggestive of CMV compromise. We did not include asymptomatic outpatients as in other Chilean studies ${ }^{6}$. Our approach allows a better estimation of a numerical value able to separate those diseased from those infected because a real clinical scenario was considered. A recent study in Brazil determined a cut- 

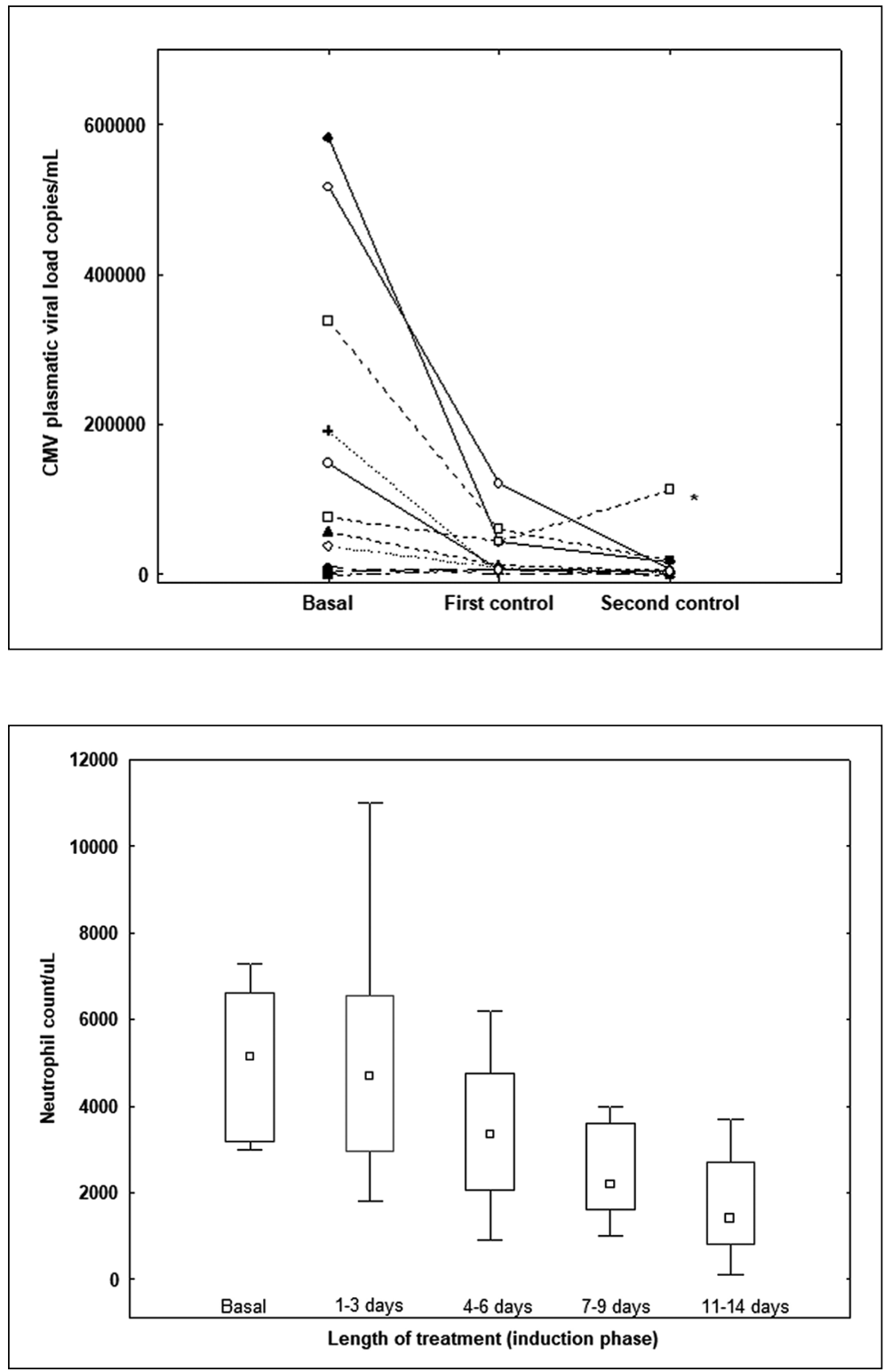

Figure 2. Viral clearence: plasmatic CMV viral load values among 11 patients treated with GCV or valGCV and who had at least one follow up control. The patient marked by an asterix showed a transient CMV VL increase after GVC dosing was diminished by bone marrow toxicity.
Figure 3. Neutrophil count evolution among 8 patients treated with GCV or valGCV for CMV illness who presented bone marrow toxicity. Data obtained during induction therapy. Box indicates median values and $25 \%-75 \%$ interquartile range. Extreme values are denoted by horizontal bars. off point of 5,010 copies/mL similar to our value of 3,800 copies $/ \mathrm{mL}^{5}$, although with lower sensitivity (76.9\% versus $91.6 \%$ in our study) and specificity (76.9\% versus $100 \%)$. Variations in the type of sample used (whole blood, leukocytes or plasma), the type of immunosuppressed patients included and the characteristics of the control group determine that the quantitative measurement of CMV must be evaluated in each center. In our case, the high sensitivity and specificity obtained support this technique to be incorporated into clinical decision-making in patients with AIDS and CMV suspicion. Quantification of CMV is necessary due to the wide differential diagnosis in AIDS patients who present with fever, diarrhea with or without thrombocytopenia/leukopenia and that include, disseminated mycobacteriosis, myelodysplastic syndrome, lymphoma with intestinal involvement, enteric infections by community, opportunistic, or nosocomials agents like Clostridiodes difficile. 
A quarter of our patients debuted with AIDS and CMV illness without knowing their diagnosis, and an additional quarter knew their diagnosis but were not in control and had never received ART. These data are compatible with a Chilean report indicating that $22 \%$ of patients with HIV infection debut with AIDS $^{12}$. The trend towards an increase in annual hospitalizations for CMV illness and AIDS in our center is in concert with the uncontrolled HIV epidemic in Chile. A recent increase in CMV in these patients has been reported in other countries ${ }^{13}$.

Our work indicates that CMV is a relevant OI agent causing hospital admissions or accompanying other OI even in the ART era. Appears in patients with low CD4 counts, and its predominant clinical presentation is the gastrointestinal compromise. In addition, cases may be accompanied by thrombocytopenia, leukopenia or increased serum transaminases. The absence of retinitis in our series has also been described by other authors ${ }^{13}$ The absence of CMV-associated pneumonia events is in part explained by a limited access to fiberbronchoscopy in our center. Fortunately, for most patients the prognosis is favorable and is accompanied by clinical improvement and viral clearance. We observed 2 cases with a cholestatic pattern previously described in the literature ${ }^{14}$. CMV may also contribute to death and the deceased patient observed in our series shared the same risk factors described in the literature for a fatal outcome: admission to the ICU and connection to mechanical ventilation ${ }^{13}$.

Treatment with intravenous GVC or valGCV was accompanied by a progressive decrease in the neutrophil count, making periodic monitoring of its values imperative. Less frequently, we observed the appearance of thrombocytopenia and nephrotoxicity. These adverse effects are known and have been described in the literature and reversible with drug withdrawal ${ }^{10,15,16}$. Foscarnet is an alternative to GCV/valGCV but is associated to a higher rate of adverse reactions ${ }^{17}$. In our series, this alternative was not necessary. ValGCV was used instead of GCV during the induction phase in a minority of patients despite its oral route. Three limitations hamper a more universal application for this outpatient-based alternative: a) limited bioavailability by diarrhoea, a symptom present in half of our patients; b) a higher direct cost when compared to intravenous GCV (115 vs 51 USD for year 2002) ${ }^{18}$ with a $33 \%$ more expensive cost for our institution at year 2018 (138 vs 104 US dollars for a daily treatment) and c) illness severity that impede using the oral route (around 40\% of our case series required admission to critical care units).

The small number of cases included in this work impeded a more thoroughly statistical analysis and to identify risk factors for an adverse outcome, recurrence or drug toxicity. Notwithstanding, it allowed to delineate a useful molecular tool for the diagnosis and follow up of CMV diseased patients, to define frequent clinical syndromes associated to CMV in AIDS patients and to assess possible outcomes and drug toxicity.

In conclusion, $\mathrm{CMV}$ is an opportunistic agent that affects AIDS patients with low CD4 lymphocyte counts, being able to cause hospitalizations or complications after admission for other reasons. Its predominant clinical manifestation in our series was gastrointestinal. CMV VL is useful to discriminate infected patients from those with illnesses and the cut-off level in our center was 3,800 copies/mL. Leukopenia and thrombocytopenia are frequent in these cases. The response to treatment and prognosis is favorable in most cases. However, CMV is associated with surgical interventions, transfusion requirements, admission to ICU and treatment is associated with hematological toxicity in some patients. A fatal outcome is possible.

\section{References}

1. Cáceres K. Situación de las infecciones de transmisión sexual en Chile, 2017. Rev Chilena Infectol 2019; 36 (2): 221-33.

2. Kaplan JE, Hanson D, Dworkin MS, Frederick T, Bertolli J, Lindegren ML, et al. Epidemiology of human immunodeficiency virus-associated opportunistic infections in the United States in the era of highly active antiretroviral therapy. Clin Infect Dis 2000; 30 (Suppl 1): S5-14.

3. Palella FJ, Delaney KM, Moorman AC, Loveless MO, Fuhrer J, Satten GA, et al. Declining morbidity and mortality among patients with advanced human immunodeficiency virus infection. N Engl J Med 1998; 338 (13): 853-60.

4. Mizushima D, Nishijima T, Yashiro S, Teruya K, Kikuchi Y, Katai N, et al. Diagnostic utility of quantitative 
plasma cytomegalovirus DNA PCR for cytomegalovirus end-organ diseases in patients with HIV-1 infection. J Acquir Immune Defic Syndr 2015; 68 (2): 140-6.

5. Carstensen S, Mara Raboni SM, França JCB, Teixeira F. Standardization of antigenemia and qPCR cut-off values in whole blood for the detection of cytomegalovirus disease in HIV patients. Rev Soc Bras Med Trop 2019; 52: e20180457.

6. Luchsinger V, Vásquez P, Silva M, Bruno MJ, Siches I, Villarroel J, et al. Antigenemia y reacción de polimerasa en cadena en tiempo real en el diagnóstico de enfermedad por citomegalovirus en adultos con virus de inmunodeficiencia adquirida. Rev Chilena Infectol 2015; 32 (6): 664-71.

7. Farfán M, Torres JP, Vergara A, Donoso G, Alba A, Paris $\mathrm{C}$, et al. Comparación de las técnicas de reacción de polimerasa en cadena en tiempo real y antigenemia para la detección de citomegalovirus en sangre de niños sometidos a trasplante. Rev Chilena Infectol 2011; 28 (2): 113-7.

8. Parada MT, Alba A, Sepúlveda C. Early and late infections in lung transplantation patients. Transplant Proc 2010: 42 (1): 333-5.

9. Ljungman P, Boeckh M, Hirsch HH, Josephson F, Lundgren J, Nichols G, et al. Definitions of cytomegalovirus infection and disease in transplant patients for use in clinical trials. Clin Infect Dis 2017; 64 (1): 87-91.

10. Levinson ML, Jacobson PA. Treatment and prophylaxis of cytomegalovirus disease. Pharmacotherapy 1992; 12 (4): 300-18.
11. Khwaja A. KDIGO Clinical Practice Guideline for Acute Kidney Injury. Nephron Clin Pract 2012; 120: c179-84.

12. Beltran C, Zitko P, Wolff M, Bernal F, Asenjo A, Fernández AM, et al. Evolución de las características epidemiológicas y clínicas de pacientes adultos del programa nacional al inicio de la terapia anti-retroviral en la Cohorte Chilena de SIDA, 2001-2015. Rev Chilena Infectol 2016; 33 (Supl 1): 2-10.

13. Perello R, Vergara A, Monclus E, Jiménez S, Montero $\mathrm{M}$, Saubi N, et al. Cytomegalovirus infection in HIV-infected patients in the era of combination antiretroviral therapy. BMC Infectious Diseases 2019; 19: 1030.

14. Ouandaf A, Chergui H, Seffar M, Chocho Z, Marcil S, Ouazzani $\mathrm{H}$, et al. Cytomegalovirus cholestasis in an immunocompetent host. Ann Biol Clin (Paris) 2019; 77 (3): 323-6.

15. Paul S, Dummer S. Topics in Clinical Pharmacology: Ganciclovir. Am J Med Sci 1992; 304 (4): 272-7.

16. Markham A, Faulds D. Ganciclovir. An update of its therapeutic use in cytomegalovirus infection. Drugs 1994; 48 (3): 455-84.

17. Lewis RA, Clogston P, Fainstein V, Gross R, Samo T, Tuttle C, et al. Morbidity and toxic effects associated with ganciclovir or foscarnet therapy in a randomized cytomegalovirus retinitis trial. Arch Intern Med 1995; 155 (1): 65-74.

18. Segarra-Newhman M, Salazar MI. Valganciclovir: a new oral alternative for cytomegalovirus retinitis in human immunodeficiency-seropositive individuals. Pharmacotherapy 2002; 22 (9): 1124-28. 